\title{
Fabrication, Characterization, and Optimization of CdS and CdSe Quantum Dot-Sensitized Solar Cells with Quantum Dots Prepared by Successive Ionic Layer Adsorption and Reaction
}

\author{
H. K. Jun, M. A. Careem, and A. K. Arof \\ Centre for Ionics University of Malaya, Department of Physics, University of Malaya, 50603 Kuala Lumpur, Malaysia \\ Correspondence should be addressed to A. K. Arof; akarof@um.edu.my
}

Received 25 September 2013; Revised 31 March 2014; Accepted 1 April 2014; Published 23 April 2014

Academic Editor: Jimmy C. Yu

Copyright (C) 2014 H. K. Jun et al. This is an open access article distributed under the Creative Commons Attribution License, which permits unrestricted use, distribution, and reproduction in any medium, provided the original work is properly cited.

\begin{abstract}
$\mathrm{CdS}$ and CdSe quantum dot-sensitized solar cells (QDSSCs) were used for the study of determining the optimum preparation parameters that could yield the best solar cell performance. The quantum dots (QDs) were coated on the surface of mesoporous $\mathrm{TiO}_{2}$ layer deposited on FTO substrate using the successive ionic layer adsorption and reaction (SILAR) method. In this method the QDs are allowed to grow on $\mathrm{TiO}_{2}$ by dipping the $\mathrm{TiO}_{2}$ electrode successively in two different solutions for predetermined times. This method allows the fabrication of QDs in a facile way. Three preparation parameters that control the QD fabrication were investigated: concentration of precursor solutions, number of dipping cycles (SILAR cycles), and dipping time in each solution. CdS based QDSSC showed optimum performance when the QDs were prepared from precursor solutions having the concentration of $0.10 \mathrm{M}$ using 4 dipping cycles with the dipping time of 5 minutes in each solution. For CdSe QDSSC, the optimum performance was achieved with QDs prepared from $0.03 \mathrm{M}$ precursor solutions using 7 dipping cycles with $30 \mathrm{~s}$ dipping time in each solution. The QDs deposited on $\mathrm{TiO}_{2}$ surface were characterized using UV-vis absorption spectroscopy, FESEM, and TEM imaging.
\end{abstract}

\section{Introduction}

The rise of carbon footprint has triggered people to think of ways to reduce the carbon emission. As a result, more green technology researches are being promoted by global research communities. One of the solutions is the use of renewable energy. Among the renewable energy options, solar cells have the potential to generate electricity with minimal carbon emission. In the past decade, dye-sensitized solar cells (DSSCs) have been deeply investigated as a possible low cost alternative to the costly conventional solar cells [13]. This was followed by the introduction of semiconductor quantum dots (QDs) as an alternative light absorber to replace the widely used expensive inorganic dyes in DSSCs [4]. Among the various semiconductors suitable for QD absorbers, II-VI compound semiconductors such as CdS and CdSe are the most widely researched [5]. Many quantum dotsensitized solar cells (QDSSCs) using these QDs have been reported [6-11]. The rapid development of QDSSCs is due to the advantages of the QD itself. Among the advantages of QD as light absorber are tunable energy gaps, ability of multiple exciton generation, low fabrication cost, and high absorption coefficient $[12,13]$.

The main process of fabricating a QDSSC is the QDs attachment onto a wide band gap meso/nanoporous semiconducting film. QD synthesis and surface adsorption can be achieved via several routes [14]. The most common route is the wet chemical process such as chemical bath deposition (CBD) $[10,15]$ and successive ionic layer adsorption and reaction (SILAR) $[8,16]$. Among the two methods, SILAR appears to be an easier and effective route to fabricate QD sensitizers. The SILAR technique has been widely used to fabricate CdS QDs due to its simplicity $[8,17]$. It has the advantage of depositing QDs with controlled size and volume by varying the parameters such as precursor concentration (cationic and anionic solution), number of dipping cycles, and dipping time. Different parameters used appear to give different cell performances [18-21]. However, there are not many reports on the fabrication and optimization of CdSe 
QDs using SILAR route and this motivated the undertaking of this study.

In this study, SILAR method was used to deposit CdS and CdSe QDs on $\mathrm{TiO}_{2}$ surface which has been chosen as the base material in the photoanode. The processing parameters to fabricate QDs were varied in order to obtain solar cell performance of optimum efficiency. The varying parameters were concentration of precursor solutions, number of SILAR cycles, and dipping time in each solution. Optimum parameter settings for the synthesis of CdS and CdSe QDs by SILAR method are anticipated.

\section{Experimental}

2.1. Materials. Titanium dioxide $\left(\mathrm{TiO}_{2}\right)$ paste (PST-18NR) was purchased from JGC C\&C, Japan. Platinum catalyst solution (plastisol) and fluorine doped tin oxide (FTO) conducting glass $(8 \Omega / \mathrm{sq}$ sheet resistance) were obtained from Solaronix, Switzerland. Di-isopropoxytitanium bis(acetylacetonate) solution for the preparation of $\mathrm{TiO}_{2}$ compact layer was procured from Sigma-Aldrich and diluted with ethanol to obtain a $0.38 \mathrm{M}$ solution. Cadmium nitrate tetrahydrate, selenium dioxide, sodium borohydride, potassium chloride, and sulfur were all procured from Sigma-Aldrich while sodium sulfide nonahydrate was obtained from Bendosen, Germany.

2.2. $\mathrm{TiO}_{2}$ Electrode and Counter Electrode Preparation. FTO conducting glasses were used as substrates for both working and counter electrodes. To prepare the working electrode or photoanode, di-isopropoxytitanium bis(acetylacetonate) solution was firstly spin coated on the FTO glass in order to form a thin $\mathrm{TiO}_{2}$ compact layer. Spin coating was performed at $3000 \mathrm{rpm}$ for 10 seconds. The compact layer coated FTO glasses were then sintered at $450^{\circ} \mathrm{C}$ for 30 minutes. $\mathrm{TiO}_{2}$ paste was subsequently deposited on top of the compact layer using the doctor blade method. The newly deposited layer was sintered at $450^{\circ} \mathrm{C}$ for 30 minutes in order to remove any organic residues and moisture as well as to obtain a nanoporous $\mathrm{TiO}_{2}$ layer. The $\mathrm{TiO}_{2}$ compact layer obtained using di-isopropoxytitanium bis(acetylacetonate) will improve the adhesion of $\mathrm{TiO}_{2}$ to the substrate and at the same time provide a larger $\mathrm{TiO}_{2} / \mathrm{FTO}$ contact area ratio. The deposited compact layer also can prevent electron recombination in the solar cell by minimizing the contact between the redox electrolyte and the conductive FTO surface [16].

Platinum counter electrodes were prepared by spin coating a thin layer of plastisol solution on a FTO conducting surface. The electrodes were then sintered at $450^{\circ} \mathrm{C}$ for 30 minutes.

\subsection{Preparation of CdS and CdSe QD-Sensitized Electrodes.} $\mathrm{CdS}$ and CdSe QDs were deposited on $\mathrm{TiO}_{2}$ surface of the working electrode using the SILAR technique. Appropriate cationic and anionic precursor solutions were prepared prior to the depositions of QDs. Precursor solutions used were $\mathrm{Cd}\left(\mathrm{NO}_{3}\right)_{2}$ in ethanol, $\mathrm{Na}_{2} \mathrm{~S}$ in methanol, and $\mathrm{SeO}_{2}$ in ethanol. For the preparation of CdS QD, the $\mathrm{TiO}_{2}$ coated FTO glass was first dipped into a $\mathrm{Cd}\left(\mathrm{NO}_{3}\right)_{2}$ ethanolic solution of selected concentration for a defined period. This was followed by ethanol rinsing and drying before dipping into the same concentration of $\mathrm{Na}_{2} \mathrm{~S}$ methanolic solution for the same defined period. The process was completed with methanol rinsing and drying. The two dipping and rinsing processes are defined as one SILAR cycle. The period of dipping in each solution (half SILAR dipping process) is defined as the dipping time. After completion of the selected number of SILAR cycles, the electrodes were subjected to sintering at $400^{\circ} \mathrm{C}$ for 10 minutes under nitrogen gas flow.

For CdSe QD, SILAR process was performed in a glove box filled with argon gas adopting the procedure in the literature [19]. The $\mathrm{TiO}_{2}$ electrode was first dipped into a $\mathrm{Cd}\left(\mathrm{NO}_{3}\right)_{2}$ ethanolic solution for a defined period and followed by ethanol rinsing and drying. Then the electrode was dipped into $\mathrm{Se}^{2-}$ solution of the same concentration followed by ethanol rinsing and drying. The $\mathrm{Se}^{2-}$ solution was prepared by reacting $\mathrm{SeO}_{2}$ ethanolic solution with two parts of $\mathrm{NaBH}_{4}$. The mixture was stirred for about an hour before it was used for SILAR dipping process. In both dipping processes, the QDs prepared are referred to as $\operatorname{CdS}(n)$ and $\operatorname{CdSe}(n)$, respectively, where $n$ is the number of SILAR cycles used for preparing them.

Optical characteristics of the QD-sensitized photoelectrodes were obtained with Shimadzu PC3101 UV-vis NIR spectrophotometer. Surface morphology of the QDsensitized electrode was examined with field emission scanning electron microscopy (FESEM, Jeol JSM-7600F) and high resolution transmission electron microscopy (HR-TEM, Jeol JEM-2100F).

2.4. Preparation of Electrolyte Solutions. Polysulfide electrolyte solution for use in CdS QDSSCs was prepared by dissolving $0.5 \mathrm{M} \mathrm{Na}_{2} \mathrm{~S}, 2 \mathrm{M} \mathrm{S}$, and $0.2 \mathrm{M} \mathrm{KCl}$ in methanol/water $(7: 3 / \mathrm{v}: \mathrm{v})$ following the work by Lee and Chang [22]. For CdSe QDSSCs, the polysulfide electrolyte solution was prepared from $0.6 \mathrm{M} \mathrm{Na}_{2} \mathrm{~S}, 0.2 \mathrm{M} \mathrm{S}$, and $0.2 \mathrm{M} \mathrm{KCl}$ in water/ethanol $(7: 3 / \mathrm{v}: \mathrm{v})$ as in [18].

2.5. Assembly of QDSSCs. A sandwich-type cell was fabricated by clamping the working electrode with the counter electrode. Parafilm (130 $\mu \mathrm{m}$ thickness) was used as a spacer. Few drops of electrolyte were placed onto the surface of $\mathrm{TiO}_{2} / \mathrm{QD}$ film prior to the assembly. The effective working area of the cell was $0.25 \mathrm{~cm}^{2}$.

2.6. Photoresponse Measurements. Photocurrent-voltage (I$V$ ) characteristics of the QDSSCs were measured using a Keithley 2400 electrometer under illumination from xenon lamp at the intensity of $100 \mathrm{~mW} \mathrm{~cm}^{-2}$. Efficiency was calculated from the following equation:

$$
\eta=\frac{\left(J_{\mathrm{SC}} \times V_{\mathrm{OC}} \times \mathrm{FF}\right)}{P_{\mathrm{in}}},
$$

where $J_{\mathrm{SC}}$ is the short circuit photocurrent density, $V_{\mathrm{OC}}$ is the open-circuit voltage, FF is the fill factor, and $P_{\text {in }}$ is the power 
intensity of the incident light. $I-V$ measurements for each cell were repeated three times to ensure the consistency of the data.

\section{Results and Discussion}

3.1. SILAR Method of Preparing QDs. In this study, SILAR method has been used to fabricate CdS and CdSe QDs to sensitize the meso/nanoporous $\mathrm{TiO}_{2}$ layers. The formation and growing of the semiconductor $\mathrm{QD}$ on the $\mathrm{TiO}_{2}$ surface can be observed from the gradual colour changes taking place. As the number of SILAR cycles increased, the colour changed from lighter shade to darker shade. This change signifies the quantum confinement effects of the growing QDs [18]. Figure 1 shows the gradual colour changes of CdS and $\mathrm{CdSe}$-sensitized $\mathrm{TiO}_{2}$ films after successive increases of dipping cycles. The CdS QDs were prepared using the $0.10 \mathrm{M}$ precursor solutions with a dipping time of $5 \mathrm{~min}$ in each dipping solution. For the preparation of CdSe QDs $0.03 \mathrm{M}$ precursor solutions were used and a dipping time of $30 \mathrm{~s}$ was set for each dipping. In $\mathrm{CdS}$-sensitized $\mathrm{TiO}_{2}$ electrodes, a yellow-coloured film was obtained while, in CdSe, the colour changes were very distinct as the SILAR cycle was increased. With increasing SILAR cycles of CdSe deposition, the $\mathrm{TiO}_{2}$ film surface turned dark. This simple deposition and the growth of QDs provide an easy and controllable way for the fabrication of semiconductor-sensitized photoelectrodes.

The same colour changes were also observed with the increase of precursor concentration or dipping time, when the number of dipping cycles was kept constant. However, at higher concentration or longer dipping time, the colour change was not as distinct as that observed with the increase in number of SILAR cycles. This observation will be explained in the following section.

\subsection{Determining the Optimum Concentration for Precursor Solutions}

3.2.1. Optimum Precursor Concentration for CdS QDs. Four different precursor concentrations were used for the fabrication of CdS and CdSe QDs. For CdS QD, concentrations of $0.05 \mathrm{M}, 0.10 \mathrm{M}, 0.50 \mathrm{M}$, and $1.00 \mathrm{M}$ were used for both anion and cation precursors. Photoelectrodes were prepared from 4 dipping cycles with a dipping time of $5 \mathrm{~min}$ in each solution. Figure 2(a) shows the optical absorbance of the CdS QD-sensitized electrode prepared in a set of precursor solutions having different concentrations. It can be seen that the absorption edge shifts to higher wavelengths from $525 \mathrm{~nm}$ to $575 \mathrm{~nm}$ as the concentration of the precursor is increased from $0.05 \mathrm{M}$ to $0.50 \mathrm{M}$. However, the absorption edge is not well defined for the $1.00 \mathrm{M}$ concentration. The wavelength of the absorption edge of the QDs prepared using the precursor concentrations of $0.05 \mathrm{M}, 0.10 \mathrm{M}$, and $0.50 \mathrm{M}$ increased approximately from $520 \mathrm{~nm}$ to $540 \mathrm{~nm}$ suggesting a red-shift effect.

Band gap energy of the QDs was estimated from Tauc plot, in which $(\alpha h \nu)^{2}$ against incident photon energy, $h v$, was plotted [23-25]. Here $\alpha$ is the absorption coefficient, $h$ is the Planck's constant, and $v$ is the frequency of the incident photon. Tauc plot for CdS QD-sensitized $\mathrm{TiO}_{2}$ is shown in Figure 2(b). The band gap energy of the QD-sensitized layer is obtained by extrapolating the straight line portion to the horizontal axis. Except for $0.10 \mathrm{M}$, the band gap energy increased with the increase of precursor concentration. This suggests that a smaller sized QD particle can be obtained with a higher precursor concentration. The size of the QDs can be estimated using the following equation [26-28]:

$$
\Delta E=E_{1}-E_{g}=\left(\frac{h^{2}}{8 r^{2}}\right)\left(\frac{1}{m_{e}}+\frac{1}{m_{h}}\right),
$$

where $\Delta E$ is the band gap energy shift, $E_{1}$ is the band gap of the QD, $E_{g}$ is the band gap of the bulk materials, $r$ is the radius of the $\mathrm{QD}, h$ is the Plank's constant, and $m_{e}$ and $m_{h}$ are the effective masses of electron and hole, respectively. For CdS material, $m_{e}=0.19 m_{o}, m_{h}=0.80 m_{o}\left(m_{o}=9.11 \times 10^{-31} \mathrm{~kg}\right)$, and $E_{g}=2.25 \mathrm{eV}$ [29], while, for CdSe material, $m_{e}=0.13 m_{o}$, $m_{h}=0.44 m_{o}\left(m_{o}=9.11 \times 10^{-31} \mathrm{~kg}\right)$, and $E_{g}=1.7 \mathrm{eV}[28]$. Generally, in crystals, as the grain size increases, the band gap energy is reduced.

Figure 2(c) shows the $J-V$ curves obtained for QDSSCs fabricated with CdS QDs prepared using precursor solutions having different concentrations. The solar cell parameters obtained from these curves are listed in Table 1. The estimated band gaps and the diameters of the QDs are also indicated in this table.

It is interesting to note that CdS QD prepared from high precursor concentration does not show the highest cell efficiency. In fact, the highest efficiency is observed when CdS QDs were prepared from the precursor concentration of $0.10 \mathrm{M}$. The corresponding efficiency obtained is $1.67 \%$. Besides that, QDs prepared from $0.10 \mathrm{M}$ precursor concentration have the largest estimated size, among the samples, which corresponds to the lowest band gap energy. The diameter of the QDs which is estimated using (2) is $8.6 \mathrm{~nm}$. When the precursor concentration is high, a large number of QD nuclei are formed on the $\mathrm{TiO}_{2}$ particles. As a result, more nanosized QD particles are produced [28]. Therefore, with a higher concentration, it is suspected that the efficiency is limited due to the overloading of QDs on the top part of the $\mathrm{TiO}_{2}$ layer. QDs will tend to form aggregates near the top of the $\mathrm{TiO}_{2}$ film which will block the path for subsequent deposition of QDs in the deeper region of the film $[28,30]$. As a result, QDs deposition will continue to take place on the top surface only and the easy electron transfer from QD to the $\mathrm{TiO}_{2}$ surface will be obstructed, leading to low current generation and hence low efficiency. Fill factor of the QDSSC does not change much with various concentrations as it depends on the resistance of the cell which is mainly determined by the redox electrolyte used and its contact with QDs and counter electrode. The fill factor values obtained in this set of cells are around $30 \%$.

3.2.2. Optimum Precursor Concentration for CdSe QDs. For CdSe QD preparation, $0.01 \mathrm{M}, 0.03 \mathrm{M}, 0.05 \mathrm{M}$, and $0.10 \mathrm{M}$ precursor concentrations were used. The photoelectrodes were prepared from 6 dipping cycles with a dipping time of 

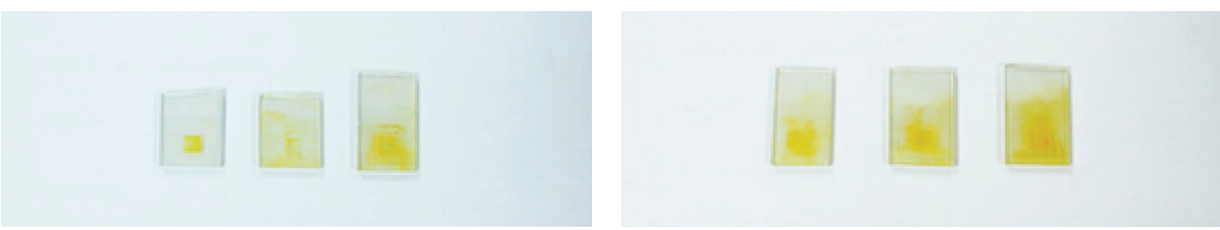

(a)
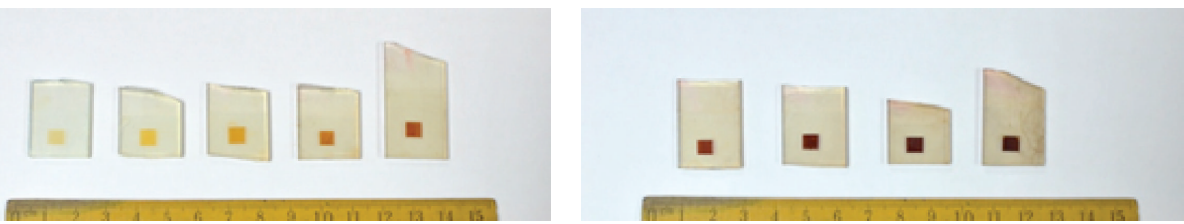

(b)

FIgURE 1: Photos of electrodes after each SILAR cycle (a) of 1-3, 5,7, and 10 cycles for CdS growth and (b) of 1-5 and 7-10 cycles for CdSe growth.

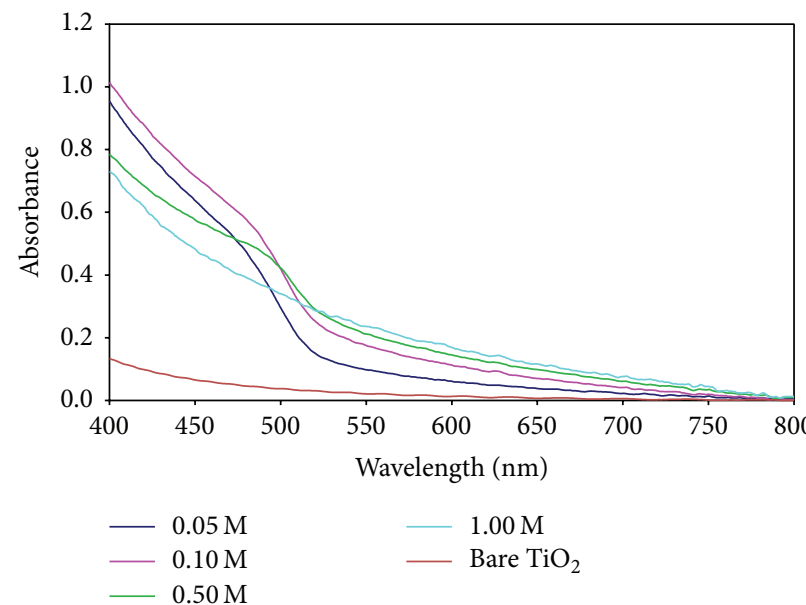

(a)

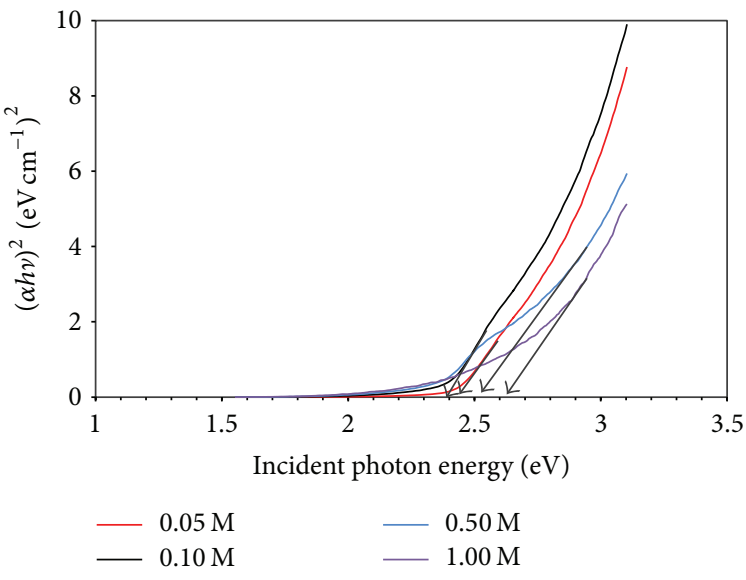

(b)

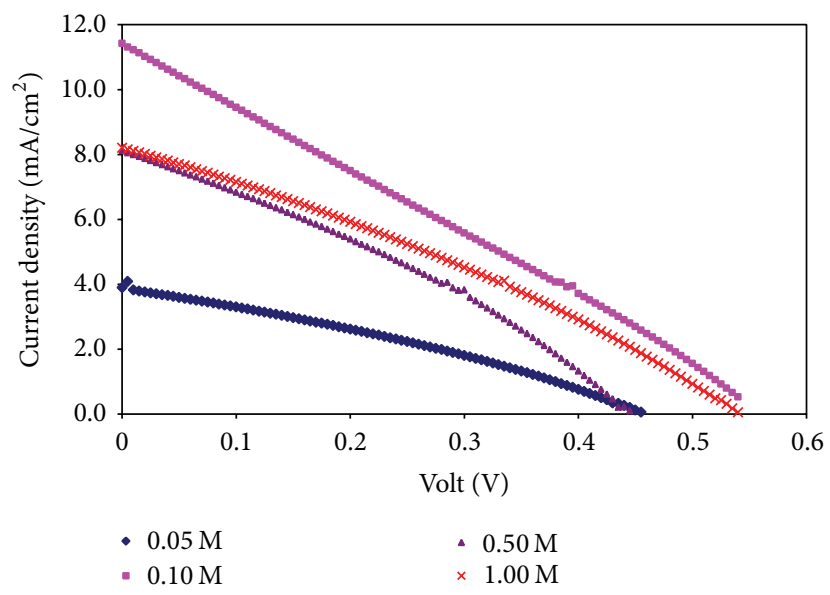

(c)

FIGURE 2: (a) UV-vis spectra, (b) Tauc plot, and (c) J-V curves of QDSSCs for CdS QDs prepared using different precursor concentrations. 
TABLE 1: The energy gap and size of QDs and QDSSC performance parameters for CdS QDs prepared using different precursor concentrations.

\begin{tabular}{lcccccc}
\hline $\begin{array}{l}\text { Precursor } \\
\text { concentration }\end{array}$ & $\begin{array}{c}\text { QD band gap } \\
(\mathrm{eV})\end{array}$ & $\begin{array}{c}\text { Estimated QD } \\
\text { diameter }(\mathrm{nm})\end{array}$ & $J_{\mathrm{SC}}\left(\mathrm{mA} / \mathrm{cm}^{2}\right)$ & $V_{\mathrm{OC}}(\mathrm{V})$ & Fill factor $(\%)$ & Efficiency, $\eta(\%)$ \\
\hline $0.05 \mathrm{M}$ & 2.43 & 7.4 & 3.90 & 0.455 & 31.6 & 0.56 \\
$0.10 \mathrm{M}$ & 2.38 & 8.6 & 11.42 & 0.565 & 25.9 & 1.67 \\
$0.50 \mathrm{M}$ & 2.53 & 5.9 & 8.12 & 0.445 & 32.0 & 1.16 \\
$1.00 \mathrm{M}$ & 2.63 & 5.1 & 8.21 & 0.540 & 31.0 & 1.37 \\
\hline
\end{tabular}

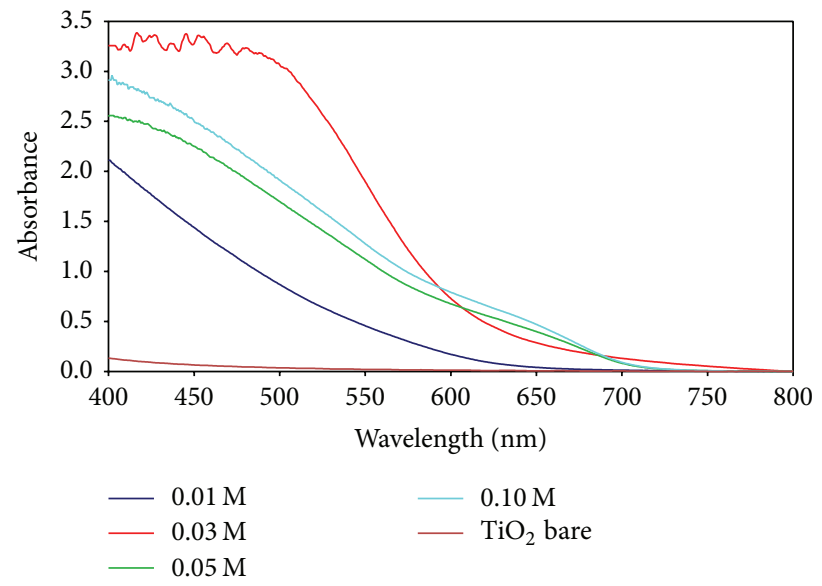

(a)

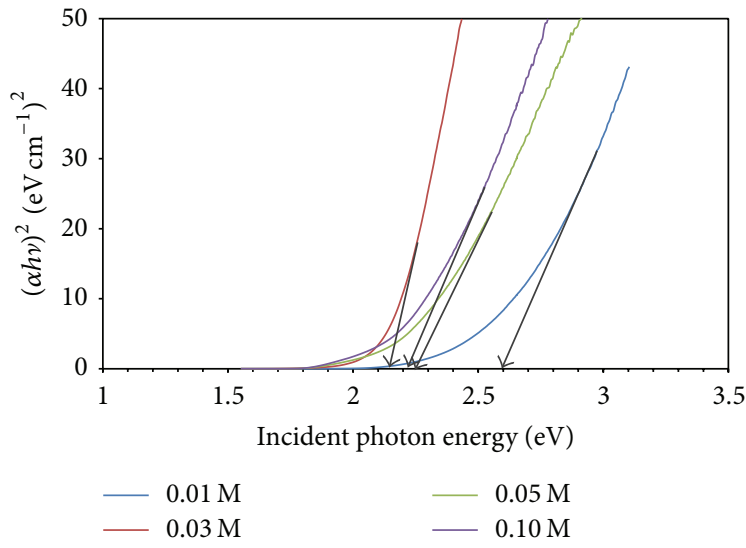

(b)

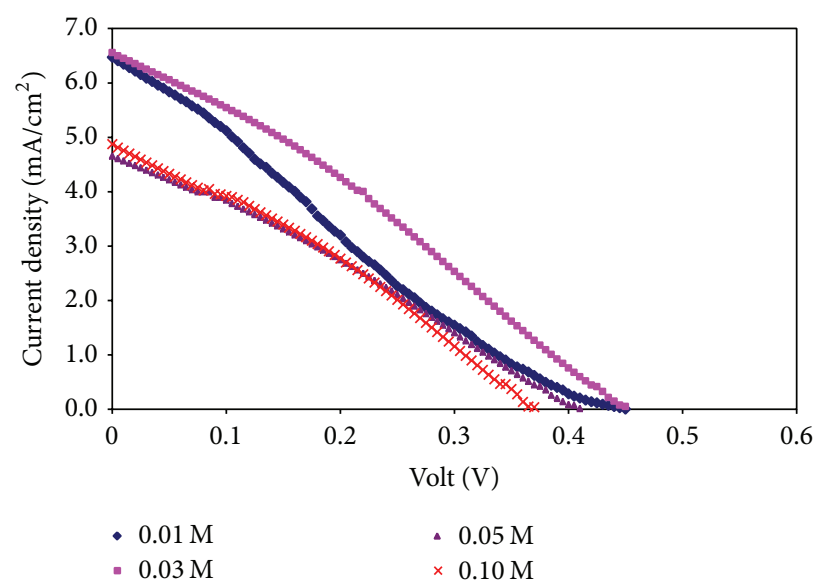

(c)

FIgURE 3: (a) UV-vis spectra, (b) Tauc plot, and (c) J-V curves of QDSSCs for CdSe QDs prepared using different precursor concentrations.

30 s. Figure 3(a) shows the UV-vis spectra of the CdSe QDs prepared from the four different precursor concentrations. The $J-V$ curves of the CdSe QDSSCs with QDs prepared from four different precursor concentrations are shown in Figure 3(c) and Table 2 summarizes the band gap energy and diameters of QDs together with the corresponding cell performance parameters.

It is observed that QDs prepared from $0.03 \mathrm{M}$ concentration have the highest absorbance although QDs prepared in $0.05 \mathrm{M}$ and $0.10 \mathrm{M}$ solutions have higher absorption edges (around $700 \mathrm{~nm}$ compared to $610 \mathrm{~nm}$ of that of $0.03 \mathrm{M}$ ). Nevertheless, with higher concentration, the absorption edge shifts to higher wavelength (in this case it is $700 \mathrm{~nm}$ ). CdSe QDs prepared from $0.03 \mathrm{M}$ precursor concentration also have the lowest band gap energy and highest diameter when compared with those obtained with other concentrations. The lowest band gap energy which is $2.15 \mathrm{eV}$ is favourable for electron conduction when excited as the electron excitation requires only little energy. This value is quite near to the bulk energy band gap of CdSe $(1.7 \mathrm{eV})$. The estimated diameter of QDs prepared from precursor concentration of $0.03 \mathrm{M}$ is about $6.0 \mathrm{~nm}$. The Tauc plots which give the approximate band gap energies are shown in Figure 3(b). The largest QDs with the lowest band gap energy give the highest QDSSC 
TABLE 2: The energy gap and size of QDs and QDSSC performance parameters for CdSe QDs prepared using different precursor concentrations.

\begin{tabular}{lcccccc}
\hline $\begin{array}{l}\text { Precursor } \\
\text { concentration }\end{array}$ & $\begin{array}{c}\text { QD band gap } \\
(\mathrm{eV})\end{array}$ & $\begin{array}{c}\text { Estimated QD } \\
\text { diameter }(\mathrm{nm})\end{array}$ & $J_{\mathrm{SC}}\left(\mathrm{mA} / \mathrm{cm}^{2}\right)$ & $V_{\mathrm{OC}}(\mathrm{V})$ & Fill factor $(\%)$ & Efficiency, $\eta(\%)$ \\
\hline $0.01 \mathrm{M}$ & 2.60 & 4.2 & 6.47 & 0.450 & 23.0 & 0.67 \\
$0.03 \mathrm{M}$ & 2.15 & 6.0 & 6.55 & 0.450 & 31.0 & 0.91 \\
$0.05 \mathrm{M}$ & 2.25 & 5.4 & 4.66 & 0.410 & 29.0 & 0.55 \\
$0.10 \mathrm{M}$ & 2.23 & 5.5 & 4.87 & 0.370 & 31.0 & 0.56 \\
\hline
\end{tabular}

TABLE 3: The energy gap and size of QDs and QDSSC performance parameters for CdS QDs prepared from various SILAR cycles.

\begin{tabular}{|c|c|c|c|c|c|c|}
\hline $\begin{array}{l}\text { Number of } \\
\text { dipping cycles }\end{array}$ & $\begin{array}{c}\text { Band gap energy } \\
(\mathrm{eV})\end{array}$ & $\begin{array}{l}\text { Estimated QD } \\
\text { diameter }(\mathrm{nm})\end{array}$ & $J_{\mathrm{SC}}\left(\mathrm{mA} / \mathrm{cm}^{2}\right)$ & $V_{\mathrm{OC}}(\mathrm{V})$ & Fill factor (\%) & Efficiency, $\eta(\%)$ \\
\hline 1 & 2.85 & 4.0 & 1.18 & 0.335 & 44.3 & 0.18 \\
\hline 2 & 2.80 & 4.2 & 6.09 & 0.485 & 31.6 & 0.93 \\
\hline 3 & 2.60 & 5.3 & 9.10 & 0.510 & 31.7 & 1.47 \\
\hline 4 & 2.38 & 8.6 & 11.42 & 0.565 & 25.9 & 1.67 \\
\hline 5 & 2.40 & 8.1 & 9.80 & 0.525 & 28.1 & 1.45 \\
\hline 7 & 2.40 & 8.1 & 6.37 & 0.505 & 33.8 & 1.09 \\
\hline 10 & 2.40 & 8.1 & 4.62 & 0.480 & 30.1 & 0.67 \\
\hline
\end{tabular}

efficiency of $0.91 \%$ with a fill factor of $31 \%$. The performance of the cells does not improve with higher precursor concentrations. This could be due to formation of QD aggregates on the $\mathrm{TiO}_{2}$ film top surface as explained above. Consequently, the short-circuit photocurrent density appears to be low.

3.3. Determining the Number of Dipping Cycles for the Best Performance. The optimum precursor concentrations found in Section 3.2 were selected for the next set of experiments in order to determine the number of SILAR dipping cycles needed to prepare QDs that would produce the best performance in QDSSCs. In the case of CdS QDs, the concentration of $0.10 \mathrm{M}$ gave the best performance while, for CdSe QDs, $0.03 \mathrm{M}$ gave the optimum result, as reported in Section 3.2.

3.3.1. Determination of Optimum Dipping Cycle for CdS QDs. For CdS QDs, SILAR dipping cycles ranging from 1 to 10 cycles were studied with precursor concentration of $0.10 \mathrm{M}$. Dipping time in each solution was fixed at $5 \mathrm{~min}$. QDs were prepared using 1-5, 7, and 10 cycles and their respective UVvis absorbance and QDSSCs were studied. As observed from the UV-vis spectra result (Figure 4(a)), the absorption edge shifts to higher wavelengths with increasing the number of dipping cycles up to 4 cycles and remains almost constant with a further increase in the number of dipping cycles. This could be linked to the number of QDs and their size deposited on the $\mathrm{TiO}_{2}$ surface. As the number of cycles increased, QDs begin to form mostly on the top part of the $\mathrm{TiO}_{2}$ layer and their number and size gradually increase and ultimately may block the growth of QDs in the inner regions of the $\mathrm{TiO}_{2}$ layer. Further increment of dipping cycles will therefore create QDs of smaller sizes on top of the QDs already formed and increase the thickness of the QD layer. This will keep the absorption edge almost at the same wavelength but increase the amount of absorption. Analysis of SEM images seems to support this hypothesis as small dot particles were observed on top of the $\mathrm{TiO}_{2}$ matrix with a larger number of dipping cycles (refer to Section 3.5 for details).

Tauc plots for the QDs are shown in Figure 4(b) while the $J-V$ curves of the CdS QDSSCs with QDs prepared using different number of SILAR dipping cycles are shown in Figure 4(c). Table 3 displays the summary of the band gap energy and diameter of the QDs as well as the performance parameters of the QDSSCs based on them.

Optimum performance was obtained for the QDSSC with QDs prepared using 4 dipping cycles. Band gap energy estimation shows an optimum value of $2.38 \mathrm{eV}$ for the QDs prepared from 4 dipping cycles. As the number of dipping cycles is increased beyond 4 cycles, there was no further improvement in the band gap energy. As for the size of the QDs formed, increased dipping cycles would result in QDs with larger diameter. The largest diameter of $8.6 \mathrm{~nm}$ for the QDs was obtained when they were prepared with 4 dipping cycles. With further increment of the number of dipping cycles, the average diameter of the QDs remains around $8 \mathrm{~nm}$ confirming that the size of the QDs does not increase but more and more smaller sized QDs are formed near the top of the $\mathrm{TiO}_{2}$ layer. The QDSSC with QDs prepared using 4 dipping cycles produced the best overall cell performance with an efficiency of $1.67 \%$ and a fill factor of $25.9 \%$.

3.3.2. Determination of Optimum Dipping Cycle for CdSe QDs. For CdSe QDs, the optimum dipping solution concentration was found to be $0.03 \mathrm{M}$ as shown in Section 3.2. This solution concentration was used to prepare CdSe QDs using SILAR dipping cycles ranging from 1 to 10 cycles. Dipping time in each solution was fixed at $30 \mathrm{~s}$. This short time frame appears to be suitable for the dipping process as much shorter period 


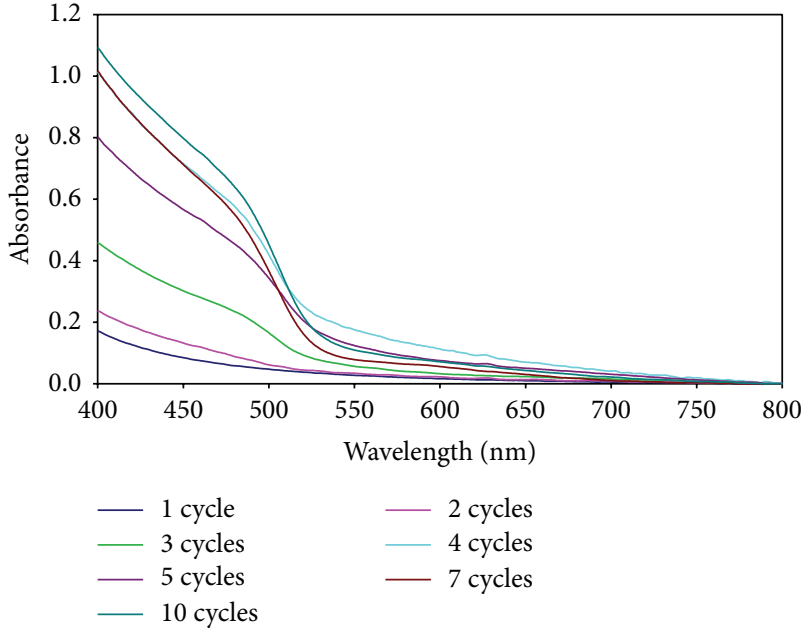

(a)

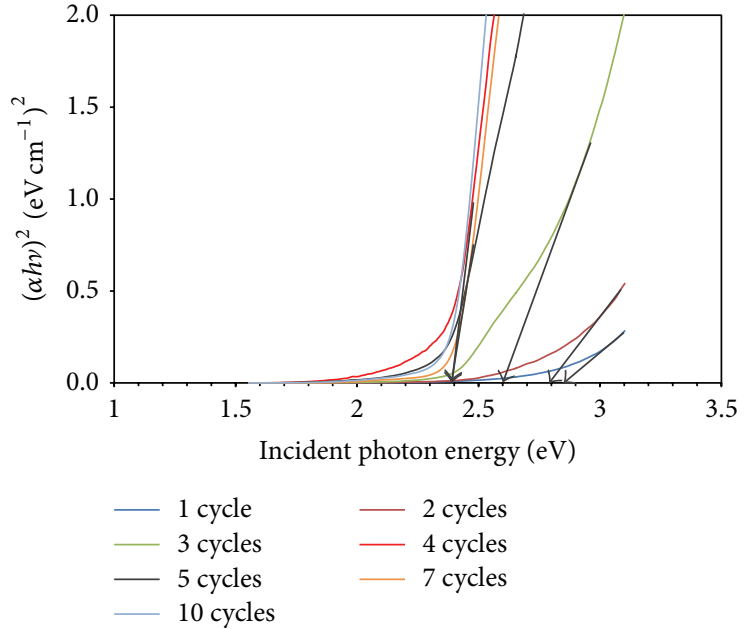

(b)

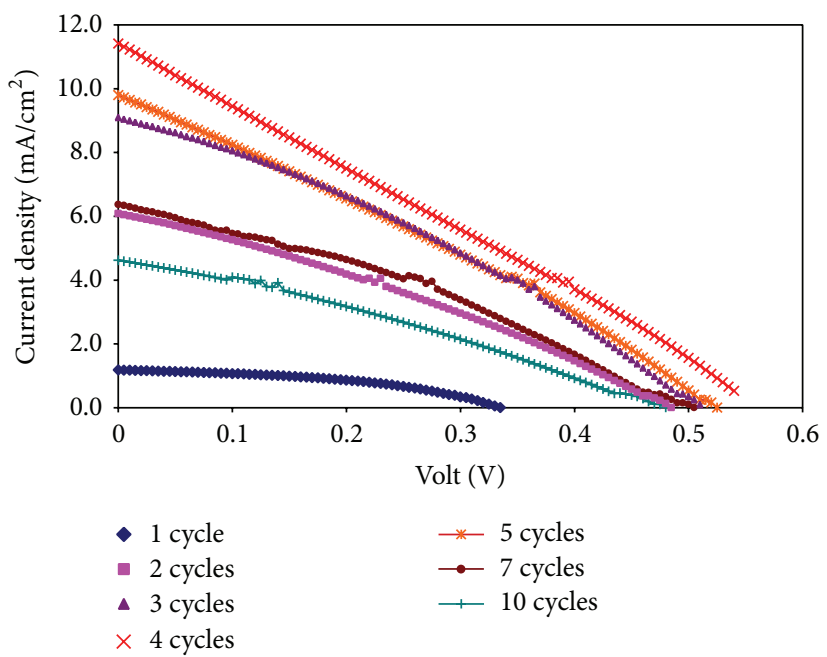

(c)

FIGURE 4: (a) UV-vis spectra, (b) Tauc plot, and (c) J-V curves of QDSSC for CdS QDs prepared using different number of SILAR cycles.

does not give sufficient time for the QDs formation on the photoanode. Figure 5(a) shows the UV-vis spectra for CdSe QD-sensitized electrodes prepared using different number of dipping cycles while Figure 5(b) shows the corresponding $(\alpha h \nu)^{2}$ versus $h v$ plots for band gap energy estimation. Similar to the observation in CdS QD electrodes, the absorption edge shifts to higher wavelengths as the number of dipping cycle is increased and reaches an optimum value for QDs prepared using 6 and 7 cycles. The estimated band gap energy for QDs obtained from 6 and 7 dipping cycles is $2.15 \mathrm{eV}$ and $2.17 \mathrm{eV}$, respectively. The corresponding diameters of these QDs are 6.0 and $5.9 \mathrm{~nm}$, respectively.

Figure 5(c) shows the J-V curves for CdSe QDSSCs with QDs prepared using different number of dipping cycles and the performance parameters of the cells with the estimated energy gaps and diameter of the QDs are tabulated in Table 4. As the number of dipping cycles increases, the performance parameters improve, reaching maximum values for cells prepared using 6-7 dipping cycles before starting decreasing. The CdSe QDSSC with CdSe QDs prepared using 6 dipping cycles does not show the highest efficiency although the QDs have the somewhat lower band gap energy. The best efficiency of $1.21 \%$ with fill factor of $28 \%$ is observed for the cell where its CdSe QDs were prepared from 7 dipping cycles. The corresponding QDs have lower band gap energy with estimated QDs size of $5.9 \mathrm{~nm}$ in diameter. At 7 dipping cycles, the $\mathrm{TiO}_{2}$ surface could have been attached with CdSe QDs optimally, giving rise to the current density of the cell. When the number of dipping cycles is increased further, the cell's efficiency decreases. This result shows that more dipping cycles do not contribute to higher performance. The poor performance of the QDSSCs with QDs prepared from large number of dipping cycles can be attributed to the overloading of the QDs on the top part of the $\mathrm{TiO}_{2}$ layer as in the case of CdS QDSSC. This is further illustrated by the increase in the size of the QDs and the decrease of the current density for QDs prepared with more than 7 cycles.

3.4. Determining the Dipping Time for the Best QDSSC Performance. The third parameter which is no less important 

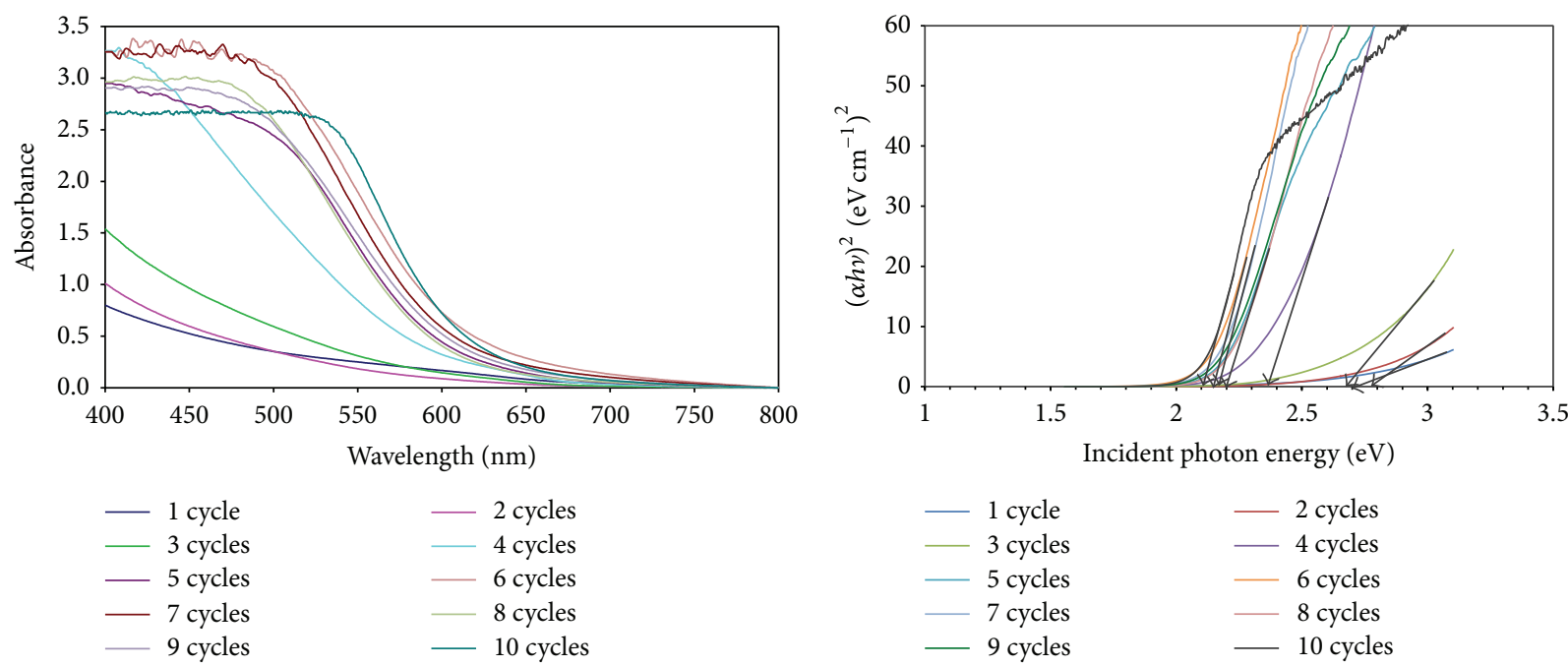

(a)

(b)

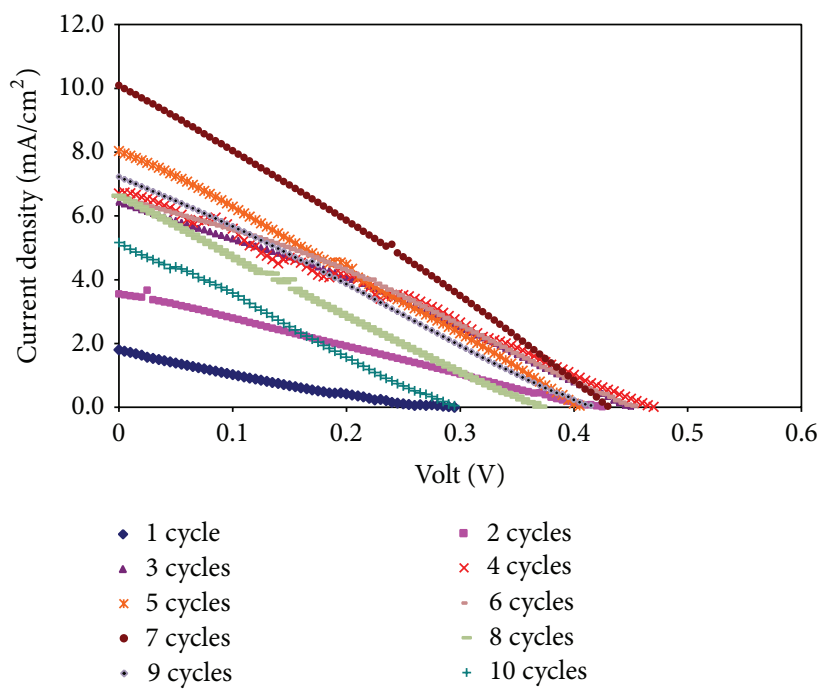

(c)

FIgURE 5: (a) UV-vis spectra, (b) Tauc plot, and (c) J-V curves of QDSSC for CdSe QDs prepared using different number of dipping cycles.

TABLE 4: The energy gap and size of QDs and QDSSC performance parameters for CdSe QDs prepared using different number of dipping cycles.

\begin{tabular}{|c|c|c|c|c|c|c|}
\hline $\begin{array}{l}\text { Number of } \\
\text { dipping cycles }\end{array}$ & $\begin{array}{c}\text { Band gap energy } \\
(\mathrm{eV})\end{array}$ & $\begin{array}{l}\text { Estimated QD } \\
\text { diameter }(\mathrm{nm})\end{array}$ & $J_{\mathrm{SC}}\left(\mathrm{mA} / \mathrm{cm}^{2}\right)$ & $V_{\mathrm{OC}}(\mathrm{V})$ & Fill factor (\%) & Efficiency, $\eta(\%)$ \\
\hline 1 & 2.70 & 3.9 & 1.80 & 0.295 & 20.0 & 0.11 \\
\hline 2 & 2.77 & 3.8 & 3.55 & 0.425 & 25.0 & 0.38 \\
\hline 3 & 2.67 & 4.0 & 6.44 & 0.450 & 30.0 & 0.87 \\
\hline 4 & 2.37 & 4.9 & 6.70 & 0.470 & 28.0 & 0.88 \\
\hline 5 & 2.17 & 5.9 & 8.04 & 0.405 & 27.0 & 0.88 \\
\hline 6 & 2.15 & 6.0 & 6.55 & 0.450 & 31.0 & 0.91 \\
\hline 7 & 2.17 & 5.9 & 10.09 & 0.430 & 28.0 & 1.21 \\
\hline 8 & 2.20 & 5.7 & 6.63 & 0.370 & 25.0 & 0.61 \\
\hline 9 & 2.16 & 6.0 & 7.23 & 0.415 & 26.0 & 0.78 \\
\hline 10 & 2.11 & 6.3 & 5.16 & 0.295 & 25.0 & 0.38 \\
\hline
\end{tabular}




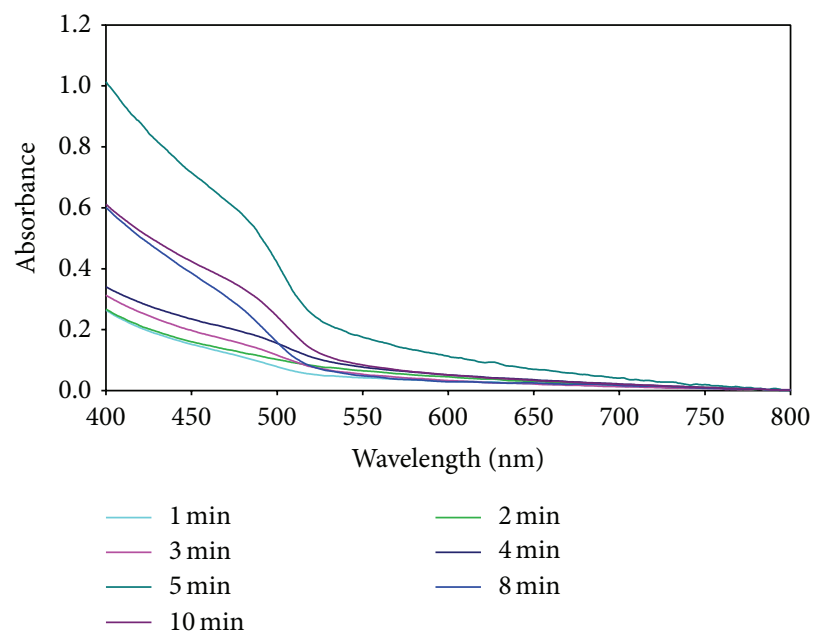

(a)

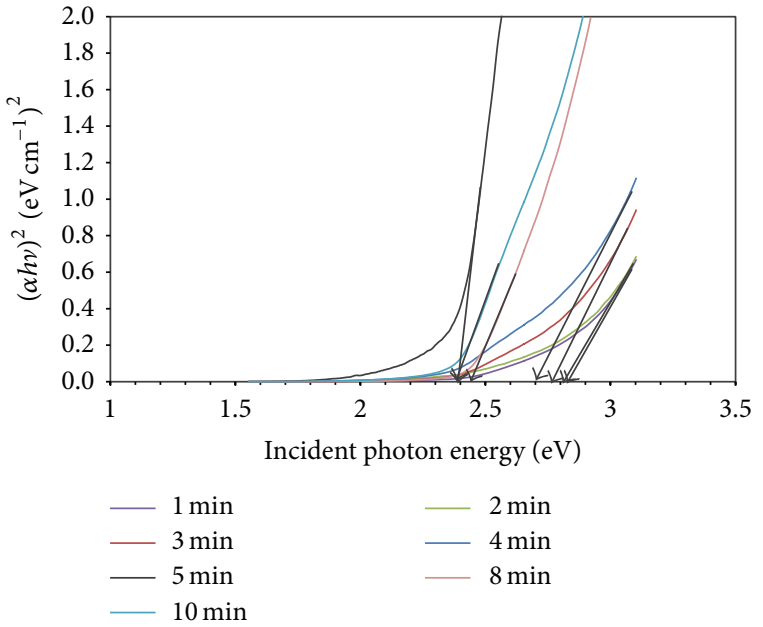

(b)

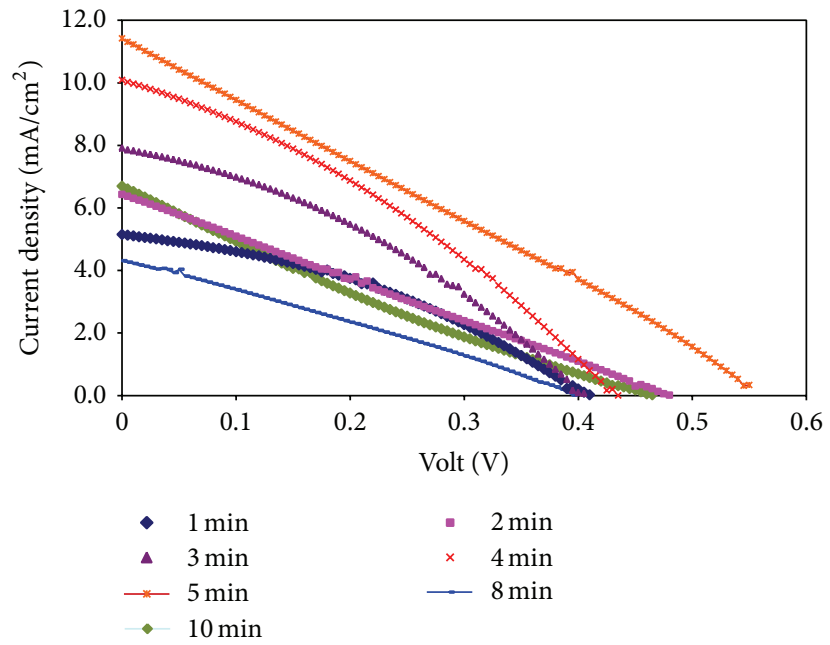

(c)

FIgURE 6: (a) UV-vis spectra, (b) Tauc plot, and (c) J-V curves of QDSSC for CdS QDs prepared using different dipping times.

is the dipping time in each solution. This parameter goes hand in hand with the number of dipping cycles as longer dipping time would require lesser number of dipping cycles and vice versa. However, the quantity and quality of QDs may vary depending on the dipping time and the number of dipping cycles. The optimum numbers of dipping cycles as determined in Section 3.3 were used for the preparation of CdS and CdSe QDs in this study.

3.4.1. Determination of Optimum Dipping Time for CdS QDs. The CdS QDs coated electrodes were prepared from solutions having a $0.10 \mathrm{M}$ concentration (both anion and cation solutions) using 4 dipping cycles with dipping time for each solution ranging from $1 \mathrm{~min}$ to $10 \mathrm{~min}$. UV-vis spectra for the CdS QD electrodes prepared using different dipping times are shown in Figure 6(a). Figure 6(b) displays the corresponding Tauc plots for band gap energy estimation. As can be seen the absorption edge shifts to higher wavelengths and reaches a maximum wavelength as the dipping time is increased and then moves to lower wavelengths with further increment of dipping time. The optimum absorption edge is observed for the electrode prepared with a 5 minute dipping time in each anion and cation solutions. This corresponds to a band gap energy of $2.38 \mathrm{eV}$, which is the lowest value within the group. The estimated diameter of the QDs corresponding to this band gap energy is $8.6 \mathrm{~nm}$.

$J-V$ curves of the QDSSCs with QDs prepared using different dipping times are shown in Figure 6(c). Table 5 shows the summary of the QD band gap energy and the performance parameters for the QDSSCs. The estimated diameters of the QDs are also shown in Table 5.

The efficiency of the QDSSC with QDs prepared using a 5 minute dipping time per solution shows the highest efficiency of $1.67 \%$ with a fill factor of $25.9 \%$. Shorter dipping times could not produce high efficiency due to the resulting low number of QDs or smaller sized QDs deposited on the $\mathrm{TiO}_{2}$ surface. Longer dipping times produce too many QDs of 
TABLE 5: The energy gap and size of QDs and QDSSC performance parameters for CdS QDs prepared using various dipping times.

\begin{tabular}{|c|c|c|c|c|c|c|}
\hline Dipping time & $\begin{array}{c}\text { Band gap energy } \\
(\mathrm{eV})\end{array}$ & $\begin{array}{l}\text { Estimated QD } \\
\text { diameter }(\mathrm{nm})\end{array}$ & $J_{\mathrm{SC}}\left(\mathrm{mA} / \mathrm{cm}^{2}\right)$ & $V_{\mathrm{OC}}(\mathrm{V})$ & Fill factor (\%) & Efficiency, $\eta(\%)$ \\
\hline $1 \mathrm{~min}$ & 2.84 & 4.1 & 5.15 & 0.410 & 37.5 & 0.79 \\
\hline $2 \mathrm{~min}$ & 2.82 & 4.1 & 6.43 & 0.480 & 25.5 & 0.79 \\
\hline $3 \min$ & 2.77 & 4.3 & 7.92 & 0.405 & 35.1 & 1.13 \\
\hline $4 \mathrm{~min}$ & 2.70 & 4.7 & 10.09 & 0.435 & 32.5 & 1.43 \\
\hline $5 \mathrm{~min}$ & 2.38 & 8.6 & 11.42 & 0.565 & 25.9 & 1.67 \\
\hline $8 \min$ & 2.45 & 7.0 & 4.31 & 0.395 & 27.7 & 0.47 \\
\hline $10 \mathrm{~min}$ & 2.38 & 8.6 & 6.70 & 0.465 & 21.1 & 0.66 \\
\hline
\end{tabular}

smaller sizes as in the case of 8 minutes or larger size QDs as in the case of 10 minutes which overcrowd the $\mathrm{TiO}_{2}$ surface and prevent easy electron transfer from the QDs to the $\mathrm{TiO}_{2}$ layer. Subsequently, the efficiency is affected by the QD loading.

\subsubsection{Determination of Optimum Dipping Time for CdSe} QDs. CdSe QD deposited electrodes were prepared from the solution having the optimum concentration of $0.03 \mathrm{M}$ using 7 dipping cycles with dipping times for each solution ranging from $30 \mathrm{~s}$ to $150 \mathrm{~s}$. The absorbance spectra of the electrodes and the corresponding Tauc plots for band gap energy estimation are shown in Figures 7(a) and 7(b), respectively. As the dipping time is increased, the absorption edge of the corresponding electrode shifts to the red wavelength region. The lowest band gap energy (i.e., the largest QD size) is obtained with a dipping time of $90 \mathrm{~s}$. The $J-V$ curves for the QDSSCs with QDs prepared using different dipping times are shown in Figure $7(\mathrm{c})$ and their performance parameters as well as band gaps and diameter of the QDs are given in Table 6. The efficiency of the cells decreases with the increase of dipping time. The poor performance of the cells with QDs prepared with longer dipping times could be attributed to the excessive QD aggregation on the $\mathrm{TiO}_{2}$ surface which increases the resistance for electron transfer. The best efficiency of $1.21 \%$ is obtained for the cell prepared with QDs using a 30 s dipping time.

Based on the results reported above, the most efficient CdS QDSSC can be fabricated with QDs prepared from precursor concentration of $0.10 \mathrm{M}$ using 4 SILAR dipping cycles with a $5 \mathrm{~min}$ dipping time in each solution. The estimated QD size is $8.6 \mathrm{~nm}$ in diameter. For CdSe QDSSC, the best performance cell can be obtained with QDs prepared from a precursor concentration of $0.03 \mathrm{M}$ using 7 SILAR dipping cycles with a dipping time of $30 \mathrm{~s}$ in each solution. The estimated QD size for the best performance is $5.9 \mathrm{~nm}$ in diameter. It is to be noted that the performance for CdSe QDSSC is far lower than the reported results in the literature [19]. This difference is attributed to the different photoanode setup that has been used in this work which did not include a $\mathrm{ZnS}$ passivation layer, a $\mathrm{TiO}_{2}$ scattering layer, and optimized thickness of the $\mathrm{TiO}_{2}$ layer. Also it is to be noted that CdSe QDs are difficult to attach on $\mathrm{TiO}_{2}$ surface due to high tendency of forming inhomogeneous QD distribution on the $\mathrm{TiO}_{2}$ surface [28]. Nevertheless, the results presented in this study can be used as a guideline for the preparation of efficient CdS and CdSe QDSSCs with optimized electrolytes and $\mathrm{TiO}_{2}$ layers. A more efficient QDSSC can be prepared by cosensitizing the $\mathrm{TiO}_{2}$ surface with CdS and CdSe QDs $[18,31,32]$. However, the stability of QDSSCs especially that of the photoanodes needs to be investigated. In one of such studies reported in the literature, the QDSSC lost $50 \%$ of its performance level within few days [33]. Therefore, more studies on the stability issues of QDSSCs are necessary.

3.5. Surface Morphology of the Optimized QD-Sensitized Electrode. The deposition and growth of CdS and CdSe QDs on $\mathrm{TiO}_{2}$ films were observed with FESEM imaging. Figures 8(a)-8(c) show the surface morphology of the $\mathrm{TiO}_{2}$ film with and without QD deposition. With the deposited CdS and CdSe QDs, the $\mathrm{TiO}_{2}$ particle size appears to be a little larger compared to that in the bare $\mathrm{TiO}_{2}$ film. The slight change of particle size after deposition of QDs can be attributed to the formation and growth of the QDs on the $\mathrm{TiO}_{2}$ surface. This observation comes hand in hand with the colour changes of the $\mathrm{TiO}_{2}$ mesoporous surface as explained in Section 3.1. The degree of porosity of the observed $\mathrm{TiO}_{2}$ mesoporous surface was analyzed with ImageJ software [34]. In bare $\mathrm{TiO}_{2}$, the degree of porosity is estimated to be $48.6 \%$. After the deposition of CdS QDs using 4 SILAR cycles, the degree of porosity reduced to $46.6 \%$ while, for CdSe QDs deposited using 7 SILAR cycles, the estimated value is $43.0 \%$. The reduction of the degree of porosity implies that the volume of $\mathrm{TiO}_{2}$ particles has increased as a result of QDs deposition on the surface.

To further confirm the formation and growth of QDs on the $\mathrm{TiO}_{2}$ film surface, the QD-deposited $\mathrm{TiO}_{2}$ films were scratched off from the FTO glass and suspended in ethanol solution for HR-TEM imaging study. A droplet of the suspension was placed on a grid for HR-TEM viewing. Three samples were selected for HR-TEM analysis: bare $\mathrm{TiO}_{2}$ film, CdS(4)-deposited $\mathrm{TiO}_{2}$ film, and CdSe(7)-deposited $\mathrm{TiO}_{2}$ film. The observed lattice spacing was compared to the data in JCPDS. The HR-TEM images for each sample are shown in Figures $8(\mathrm{~d})-8(\mathrm{f})$. The QD elements are shown by EDX result in Figures 8(g) and 8(h).

In bare $\mathrm{TiO}_{2}$ film, a distinct $d$-spacing of about $0.36 \mathrm{~nm}$ is observed in grains having an average size of $25 \mathrm{~nm}$. This $d$-value corresponds to the (101) plane of anatase $\mathrm{TiO}_{2}$. For the QD-deposited $\mathrm{TiO}_{2}$ film, CdS and CdSe particles are 

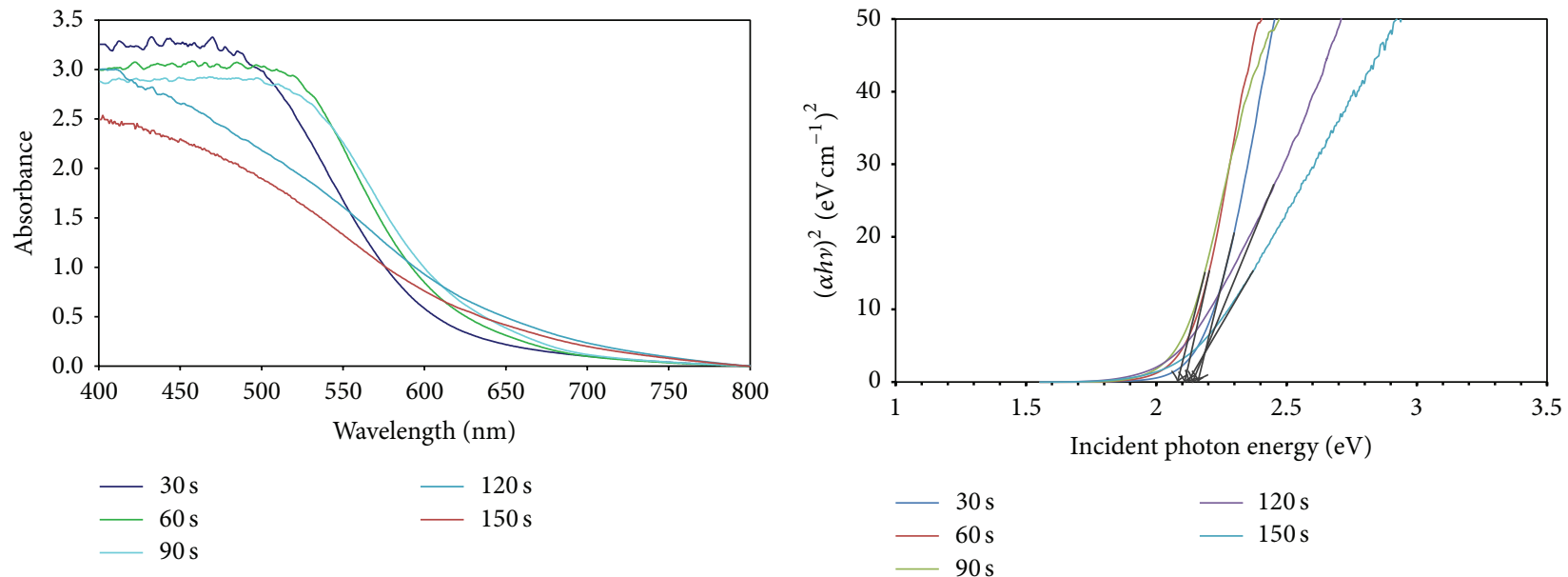

(a)

(b)

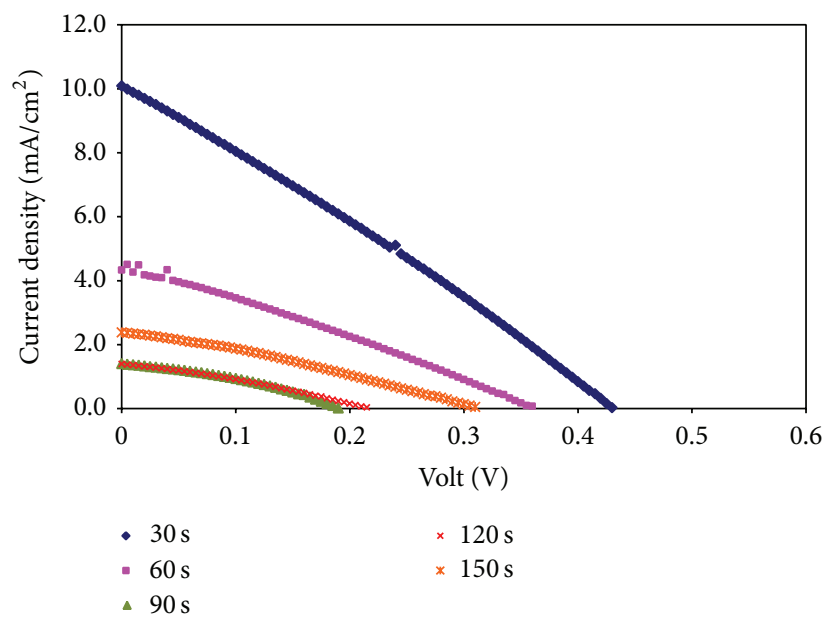

(c)

Figure 7: (a) UV-vis spectra, (b) Tauc plot, and (c) J-V curves of QDSSCs for CdSe QDs prepared using different dipping times.

observed to be attached to the $\mathrm{TiO}_{2}$ surface. In the CdSdeposited $\mathrm{TiO}_{2}$ film, $d$-spacing of $0.205 \mathrm{~nm}$ which corresponds to the (220) plane of CdS QDs attached to a $\mathrm{TiO}_{2}$ particle is observed. These CdS QDs have the size of $8.0 \mathrm{~nm}$ which is quite close to the approximate QD size obtained in Section 3.2. In the CdSe-deposited $\mathrm{TiO}_{2}$ film sample, the CdSe QDs have a $d$-spacing of $0.329 \mathrm{~nm}$. This corresponds to the (101) plane of CdSe. The estimated size of the QDs is in agreement with the QD size estimated earlier in Section 3.3 which is about $5.9 \mathrm{~nm}$.

In Section 3.3, it was pointed out that large number of dipping cycles of SILAR process could result in QD aggregation and the formation of small QDs especially in the top part of the $\mathrm{TiO}_{2}$ layer. Such a sample was prepared and investigated with FESEM imaging (Figure 8(i)). From the image, we can see the low degree of porosity of the $\mathrm{TiO}_{2}$ as compared with images in Figures 8(b) and 8(c) which are the images of $\mathrm{TiO}_{2}$ with small amounts CdS and CdSe QDs, respectively. Also there are some smaller particles dispersed randomly on the top surface in Figure 8(i) which could be the small QD formation. Such samples will not have good efficiency due to slower electron transfer from the QD to the substrate as explained above.

\section{Conclusions}

CdS and CdSe quantum dot-sensitized solar cells (QDSSCs) were fabricated using QDs prepared by SILAR method. Optimization study was performed on three quantum dot preparation parameters: concentration of precursor dipping solutions, number of dipping cycles, and dipping time for each dipping. To achieve the best performance in CdS QDSSCs, QDs must be prepared from precursor solutions each having a concentration of $0.10 \mathrm{M}$ using 4 SILAR dipping cycles with 5 minutes dipping time in each solution. For CdSe QDSSC, the optimum parameters for QD preparation are precursor solution concentration of $0.03 \mathrm{M}$ and 7 dipping cycles with a dipping time of $30 \mathrm{~s}$ in each solution. The corresponding estimated QD diameter size for CdS QD and 


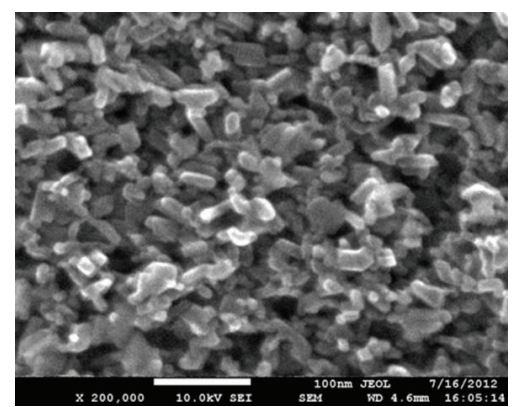

(a)

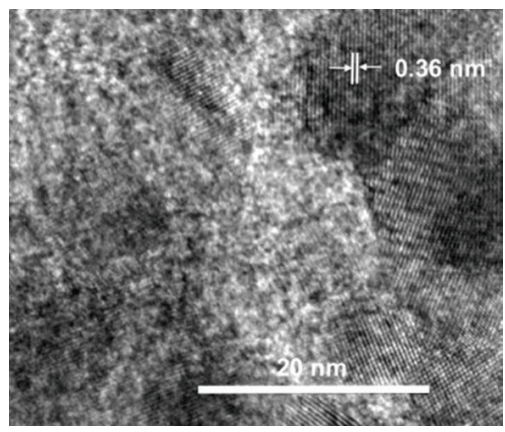

(d)

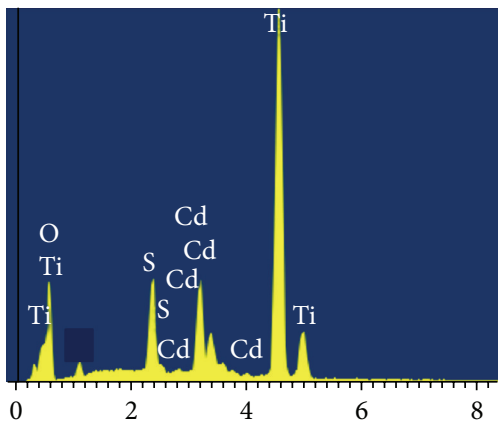

Full scale 5594 cts cursor: 0.000

(g)

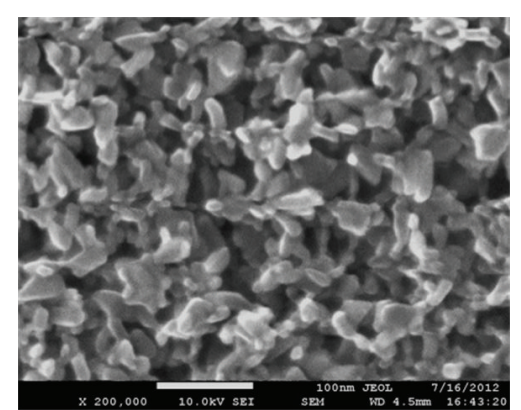

(b)

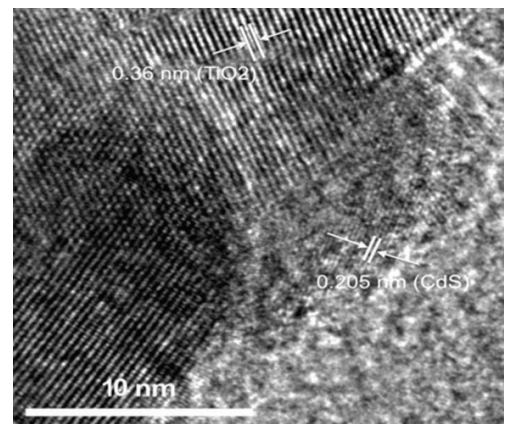

(e)

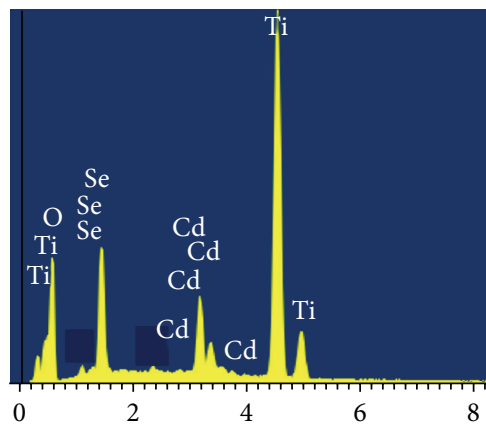

Full scale 5289 cts cursor: 0.000

(h)

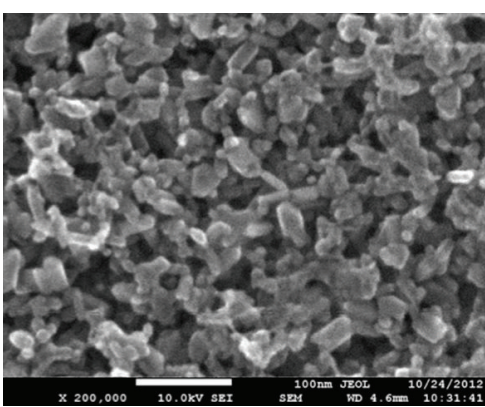

(c)

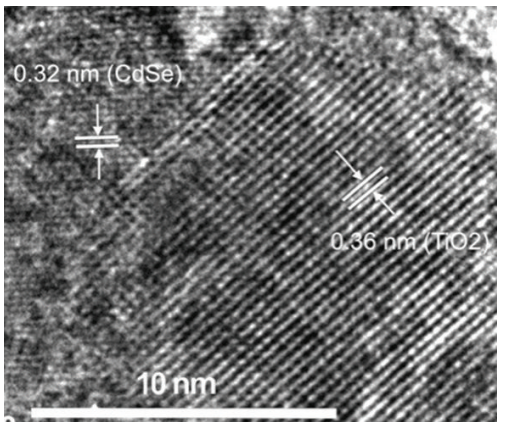

(f)

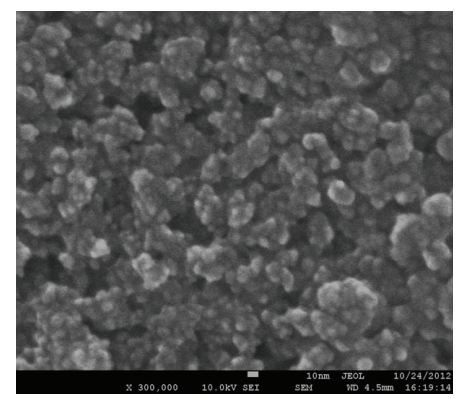

(i)

Figure 8: FESEM images of (a) bare $\mathrm{TiO}_{2}$ film surface, (b) $\mathrm{TiO}_{2}$ film with CdS(4), and (c) $\mathrm{TiO}_{2}$ film with CdSe(7); HR-TEM images of (d) bare $\mathrm{TiO}_{2}$ film surface, (e) $\mathrm{TiO}_{2}$ film with CdS(4), and (f) $\mathrm{TiO}_{2}$ film with CdSe(7); EDX result of (g) $\mathrm{TiO}_{2}$ film with CdS(4) and (h) TiO 2 film with $\mathrm{CdSe}(7)$; (i) FESEM image of $\mathrm{TiO}_{2}$ film with $\mathrm{CdS}$ produced with high dipping cycles.

TABLE 6: The energy gap and size of QDs and QDSSC performance parameters for CdSe QDs prepared using various dipping times.

\begin{tabular}{|c|c|c|c|c|c|c|}
\hline Dipping time & $\begin{array}{c}\text { Band gap energy } \\
(\mathrm{eV})\end{array}$ & $\begin{array}{l}\text { Estimated QD } \\
\text { diameter }(\mathrm{nm})\end{array}$ & $J_{\mathrm{SC}}\left(\mathrm{mA} / \mathrm{cm}^{2}\right)$ & $V_{\mathrm{OC}}(\mathrm{V})$ & Fill factor (\%) & Efficiency, $\eta(\%)$ \\
\hline $30 \mathrm{~s}$ & 2.17 & 5.9 & 10.09 & 0.430 & 28.0 & 1.21 \\
\hline $60 \mathrm{~s}$ & 2.12 & 6.3 & 4.33 & 0.360 & 29.0 & 0.45 \\
\hline $90 \mathrm{~s}$ & 2.08 & 6.6 & 1.41 & 0.190 & 36.0 & 0.10 \\
\hline $120 \mathrm{~s}$ & 2.15 & 6.0 & 1.40 & 0.215 & 31.0 & 0.09 \\
\hline $150 \mathrm{~s}$ & 2.13 & 6.2 & 2.38 & 0.310 & 30.0 & 0.22 \\
\hline
\end{tabular}

CdSe QD is $8.6 \mathrm{~nm}$ and $5.9 \mathrm{~nm}$, respectively. These diameter values are quite close to the observed particle sizes using HR-TEM. It is also observed that upon deposition of QDs, the $\mathrm{TiO}_{2}$ particles size appears to increase resulting in a reduction of porosity. Further deposition of QDs results in overcrowding near the top of the $\mathrm{TiO}_{2}$ base layer and reduces the short-circuit current density in QDSSCs and thereby limits their performance. Although the performance obtained in this study is low, higher performance is possible when proper surface passivation technique, good choice of 
counter electrode, and optimum $\mathrm{TiO}_{2}$ layer, to name a few, are applied. This study illustrates the importance of choosing the correct sized QDs and their distribution for optimizing the performance of QDSSCs.

\section{Conflict of Interests}

The authors declare that there is no conflict of interests regarding the publication of this paper.

\section{Acknowledgments}

The authors would like to thank University of Malaya for the IPPP Grant no. PV094-2012A. H. K. Jun thanks University of Malaya for the Fellowship Scheme Scholarship awarded.

\section{References}

[1] B. O’Regan and M. Grätzel, "A low-cost, high-efficiency solar cell based on dye-sensitized colloidal $\mathrm{TiO}_{2}$ films," Nature, vol. 353, no. 6346, pp. 737-740, 1991.

[2] M. Grätzel, "Dye-sensitized solar cells," Journal of Photochemistry and Photobiology C: Photochemistry Reviews, vol. 4, no. 2, pp. 145-153, 2003.

[3] M. Grätzel, "Conversion of sunlight to electric power by nanocrystalline dye-sensitized solar cells," Journal of Photochemistry and Photobiology A: Chemistry, vol. 164, no. 1-3, pp. 3-14, 2004.

[4] R. Vogel, P. Hoyer, and H. Weller, "Quantum-sized PbS, CdS, $\mathrm{Ag}_{2} \mathrm{~S}, \mathrm{Sb}_{2} \mathrm{~S}_{3}$, and $\mathrm{Bi}_{2} \mathrm{~S}_{3}$ particles as sensitizers for various nanoporous wide-bandgap semiconductors," Journal of Physical Chemistry, vol. 98, no. 12, pp. 3183-3188, 1994.

[5] H. K. Jun, M. A. Careem, and A. K. Arof, "Quantum dotsensitized solar cells-perspective and recent developments: a review of Cd chalcogenide quantum dots as sensitizers," Renewable and Sustainable Energy Reviews, vol. 22, pp. 148-167, 2013.

[6] R. Vogel, K. Pohl, and H. Weller, "Sensitization of highly porous, polycrystalline $\mathrm{TiO}_{2}$ electrodes by quantum sized CdS," Chemical Physics Letters, vol. 174, no. 3-4, pp. 241-246, 1990.

[7] L. M. Peter, D. J. Riley, E. J. Tull, and K. G. U. Wijayantha, "Photosensitization of nanocrystalline $\mathrm{TiO}_{2}$ by self-assembled layers of CdS quantum dots," Chemical Communications, no. 10, pp. 1030-1031, 2002.

[8] T. Toyoda, J. Sato, and Q. Shen, "Effect of sensitization by quantum-sized CdS on photoacoustic and photoelectrochemical current spectra of porous $\mathrm{TiO}_{2}$ electrodes," Review of Scientific Instruments, vol. 74, no. 1, pp. 297-299, 2003.

[9] D. Liu and P. V. Kamat, "Photoelectrochemical behavior of thin CdSe and coupled $\mathrm{TiO}_{2} / \mathrm{CdSe}$ semiconductor films," Journal of Physical Chemistry, vol. 97, no. 41, pp. 10769-10773, 1993.

[10] Q. Shen, D. Arae, and T. Toyoda, "Photosensitization of nanostructured $\mathrm{TiO}_{2}$ with CdSe quantum dots: effects of microstructure and electron transport in $\mathrm{TiO}_{2}$ substrates," Journal of Photochemistry and Photobiology A: Chemistry, vol. 164, no. 1-3, pp. 75-80, 2004.

[11] A. Kongkanand, K. Tvrdy, K. Takechi, M. Kuno, and P. V. Kamat, "Quantum dot solar cells. Tuning photoresponse through size and shape control of $\mathrm{CdSe}-\mathrm{TiO}_{2}$ architecture," Journal of the American Chemical Society, vol. 130, no. 12, pp. 4007-4015, 2008.
[12] P. V. Kamat, "Quantum dot solar cells. Semiconductor nanocrystals as light harvesters," Journal of Physical Chemistry C, vol. 112, no. 48, pp. 18737-18753, 2008.

[13] S. Rühle, M. Shalom, and A. Zaban, "Quantum-dot-sensitized solar cells," ChemPhysChem, vol. 11, no. 11, pp. 2290-2304, 2010.

[14] S. Emin, S. P. Singh, L. Han, N. Satoh, and A. Islam, "Colloidal quantum dot solar cells," Solar Energy, vol. 85, no. 6, pp. 12641282, 2011.

[15] T. Toyoda, I. Tsuboya, and Q. Shen, "Effect of rutile-type content on nanostructured anatase-type $\mathrm{TiO}_{2}$ electrode sensitized with CdSe quantum dots characterized with photoacoustic and photoelectrochemical current spectroscopies," Materials Science and Engineering C, vol. 25, no. 5-8, pp. 853-857, 2005.

[16] Y. Tachibana, K. Umekita, Y. Otsuka, and S. Kuwabata, "Performance improvement of CdS quantum dots sensitized $\mathrm{TiO}_{2}$ solar cells by introducing a dense $\mathrm{TiO}_{2}$ blocking layer," Journal of Physics D: Applied Physics, vol. 41, no. 10, Article ID 102002, 2008.

[17] I. Barceló, T. Lana-Villarreal, and R. Gómez, "Efficient sensitization of $\mathrm{ZnO}$ nanoporous films with $\mathrm{CdSe}$ QDs grown by Successive Ionic Layer Adsorption and Reaction (SILAR)," Journal of Photochemistry and Photobiology A: Chemistry, vol. 220, no. 1, pp. 47-53, 2011.

[18] H. J. Lee, J. Bang, J. Park, S. Kim, and S.-M. Park, "Multilayered semiconductor (CdS/CdSe/ZnS)-sensitized $\mathrm{TiO}_{2}$ mesoporous solar cells: all prepared by successive ionic layer adsorption and reaction processes," Chemistry of Materials, vol. 22, no. 19, pp. 5636-5643, 2010.

[19] H. Lee, M. Wang, P. Chen et al., "Efficient CdSe quantum dotsensitized solar cells prepared by an improved successive ionic layer adsorption and reaction process," Nano Letters, vol. 9, no. 12, pp. 4221-4227, 2009.

[20] T. Zewdu, J. N. Clifford, J. P. Hernández, and E. Palomares, "Photo-induced charge transfer dynamics in efficient $\mathrm{TiO}_{2} / \mathrm{CdS} / \mathrm{CdSe}$ sensitized solar cells," Energy and Environmental Science, vol. 4, no. 11, pp. 4633-4638, 2011.

[21] M. H. Seo, W. P. Hwang, Y. K. Kim, J. K. Lee, and M. R. Kim, "Improvement of quantum dot-sensitized solar cells based on Cds and CdSe quantum dots," in Proceedings of the 37th IEEE Photovoltaic Specialists Conference (PVSC '11), pp. 002652002655, June 2011.

[22] Y.-L. Lee and C.-H. Chang, "Efficient polysulfide electrolyte for CdS quantum dot-sensitized solar cells," Journal of Power Sources, vol. 185, no. 1, pp. 584-588, 2008.

[23] J. Tauc, "Optical properties and electronic structure of amorphous Ge and Si," Materials Research Bulletin, vol. 3, no. 1, pp. 37-46, 1968.

[24] W. Lee, S. K. Min, V. Dhas, S. B. Ogale, and S.-H. Han, "Chemical bath deposition of CdS quantum dots on vertically aligned $\mathrm{ZnO}$ nanorods for quantum dots-sensitized solar cells," Electrochemistry Communications, vol. 11, no. 1, pp. 103-106, 2009.

[25] H. Chen, W. Li, H. Liu, and L. Zhu, "A suitable deposition method of CdS for high performance CdS-sensitized $\mathrm{ZnO}$ electrodes: sequential chemical bath deposition," Solar Energy, vol. 84, no. 7, pp. 1201-1207, 2010.

[26] Q. Shen, J. Kobayashi, L. J. Diguna, and T. Toyoda, "Effect of $\mathrm{ZnS}$ coating on the photovoltaic properties of CdSe quantum dot-sensitized solar cells," Journal of Applied Physics, vol. 103, no. 8, Article ID 084304, 2008.

[27] Q. Shen and T. Toyoda, "Characterization of nanostructured $\mathrm{TiO}_{2}$ electrodes sensitized with CdSe quantum dots using 
photoacoustic and photoelectrochemical current methods," Japanese Journal of Applied Physics, Part 1: Regular Papers and Short Notes and Review Papers, vol. 43, no. 5B, pp. 2946-2951, 2004.

[28] J. Tian, R. Gao, Q. Zhang et al., "Enhanced performance of CdS/CdSe quantum dot cosensitized solar cells via homogeneous distribution of quantum dots in $\mathrm{TiO}_{2}$ Film," Journal of Physical Chemistry C, vol. 116, no. 35, pp. 18655-18662, 2012.

[29] M. Grätzel, "Photoelectrochemical cells," Nature, vol. 414, no. 6861, pp. 338-344, 2001.

[30] P. Sudhagar, J. H. Jung, S. Park et al., "The performance of coupled (CdS:CdSe) quantum dot-sensitized $\mathrm{TiO}_{2}$ nanofibrous solar cells," Electrochemistry Communications, vol. 11, no. 11, pp. 2220-2224, 2009.

[31] Y. Zhang, J. Zhu, X. Yu, J. Wei, L. Hu, and S. Dai, “The optical and electrochemical properties of $\mathrm{CdS} / \mathrm{CdSe}$ co-sensitized $\mathrm{TiO}_{2}$ solar cells prepared by successive ionic layer adsorption and reaction processes," Solar Energy, vol. 86, no. 3, pp. 964-971, 2012.

[32] R. Zhang, Q.-P. Luo, H.-Y. Chen, X.-Y. Yu, D.-B. Kuang, and C.-Y. Su, "CdS/CdSe quantum dot shell decorated vertical $\mathrm{ZnO}$ nanowire arrays by spin-coating-based SILAR for photoelectrochemical cells and quantum-dot- sensitized solar cells," ChemPhysChem, vol. 13, no. 6, pp. 1435-1439, 2012.

[33] H. K. Jun, M. A. Careem, and A. K. Arof, "A suitable polysulfide electrolyte for CdSe quantum dot-sensitized solar cells," International Journal of Photoenergy, vol. 2013, Article ID 941239, 10 pages, 2013.

[34] W. S. Rasband, "ImageJ," U. S. National Institutes of Health, Bethesda, Md, USA, 1997-2012, http://imagej.nih.gov/ij/. 

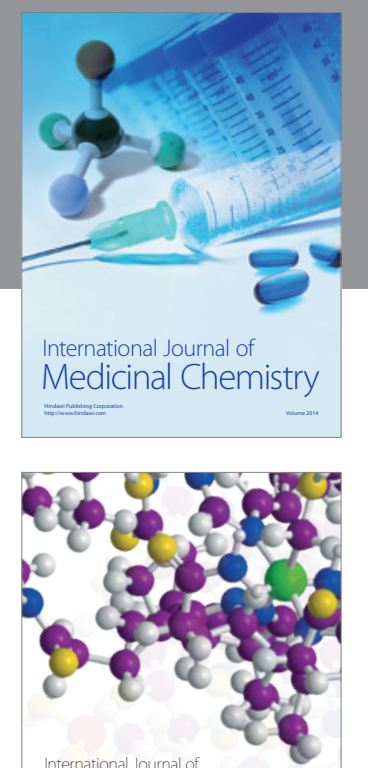

\section{Carbohydrate} Chemistry

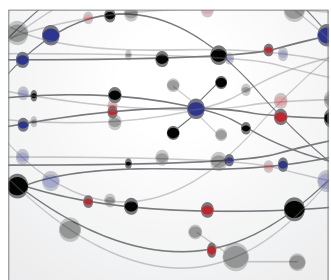

The Scientific World Journal
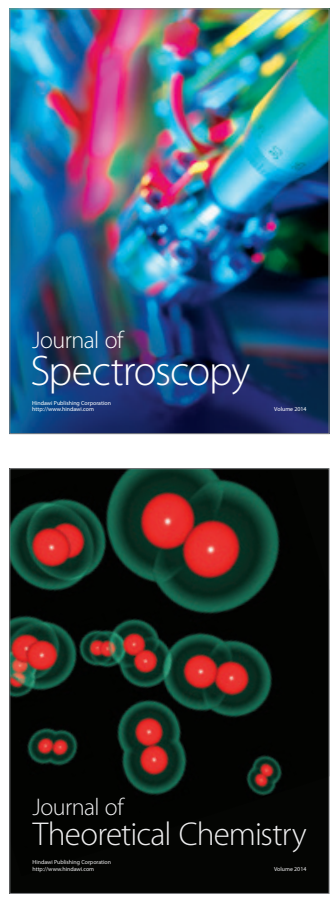
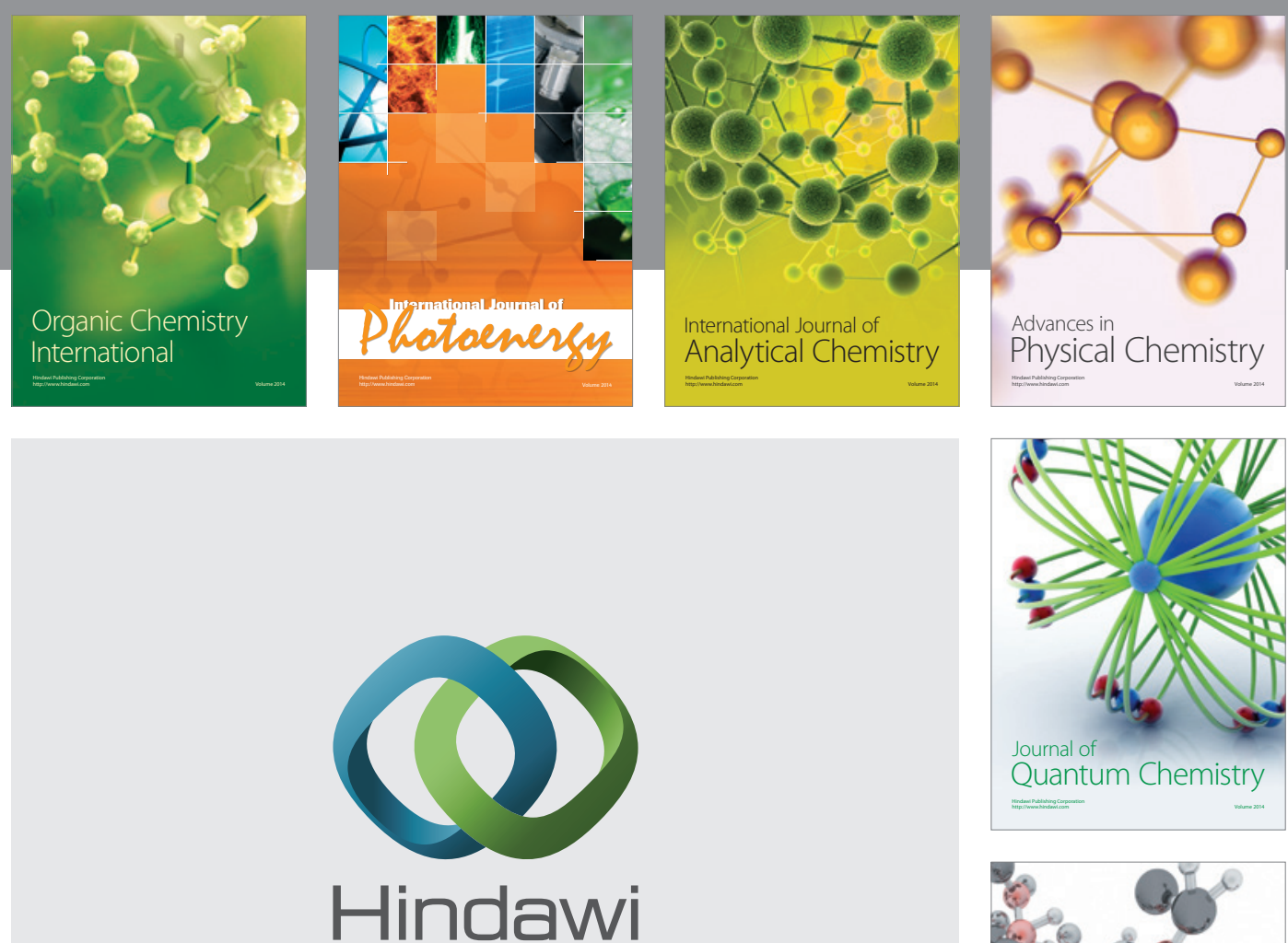

Submit your manuscripts at

http://www.hindawi.com

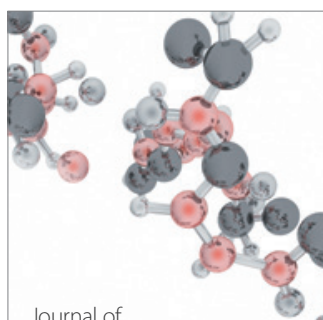

Analytical Methods

in Chemistry

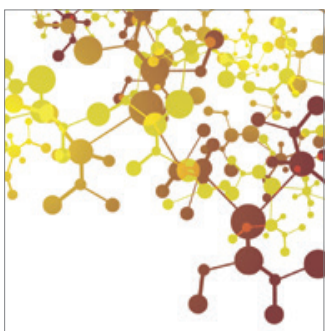

Journal of

Applied Chemistry

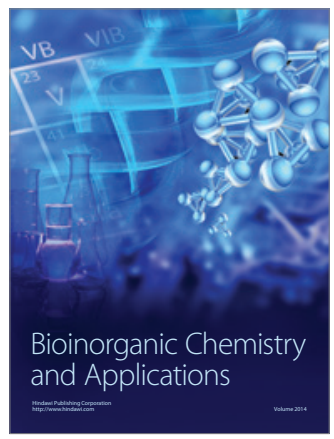

Inorganic Chemistry
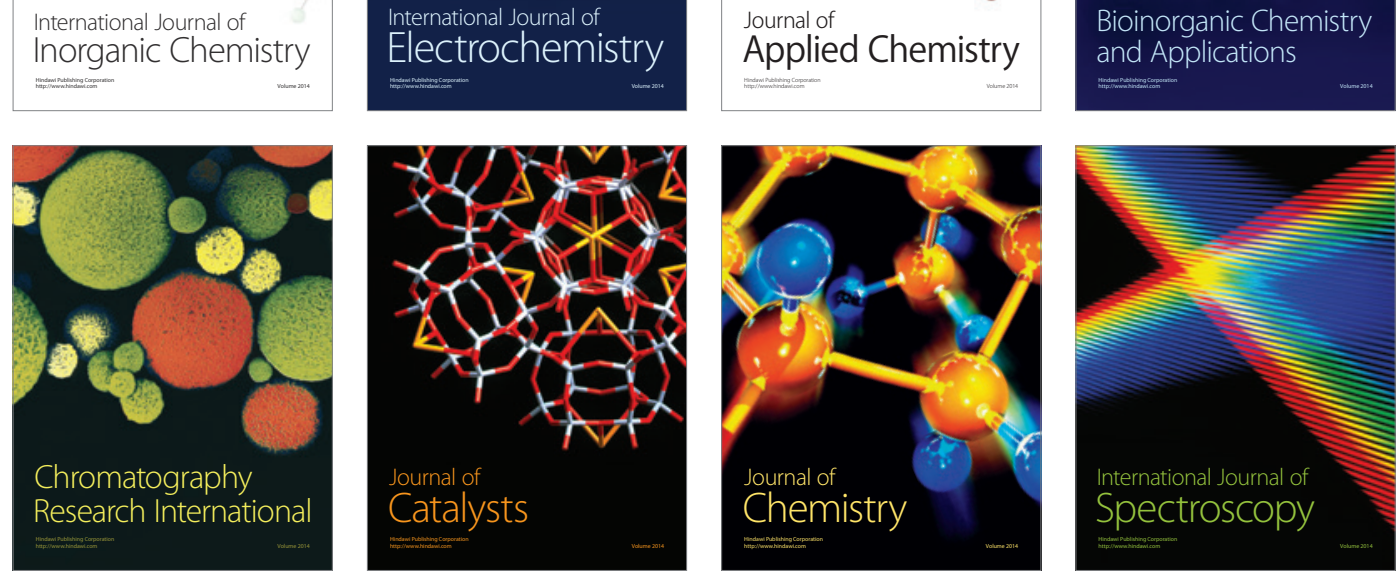